\title{
O Fenômeno do Brilho
}

\section{The Phenomenon of Shining}

DOI: http://dx.doi.org/10.12957/ek.2015.17613

Dr. Nikola Mirković

nimirkovic@gmail.com

Albert-Ludwigs-Universität

Freiburg - Alemanha

tradução Dndo. Gabriel

Lago de S. Barroso

lagobarroso@gmail.com

O artigo desenvolve uma compreensão do fenômeno do brilho que combina aspectos sociais, bem como estéticos. Primeiramente, o autor chama a atenção para o uso da expressão 'brilho' em All things shining, de Hubert Dreyfus e Sean Kelly. Dreyfus/Kelly não fornecem uma definição da expressão, mas eles situam o fenômeno do brilho na esfera social das práticas humanas. $\mathrm{O}$ artigo mostra como essa consideração pragmática é amplamente orientada pela filosofia da arte de Heidegger. Mesmo que o brilho pareça ser um tópico marginal no ensaio de Heidegger A Origem da Obra de Arte, ele se revela como essencial para o conceito heideggeriano de beleza. Na obra tardia de Heidegger sobre arte e poesia, isso se torna ainda mais evidente: o brilho aparece como presença intensificada e materialidade da obra de arte. É possível desenvolver, a partir do texto de Heidegger, uma consideração fenomenológica do brilho que saliente as qualidades sensíveis das obras de arte. Enquanto Heidegger questiona a possibilidade da arte nos tempos atuais, o autor defende (em acordo com Dreyfus e Kelly) sua atualidade contínua através da história.

PALAVRAS-CHAVE brilho . Heidegger . A Origem da Obra de Arte 


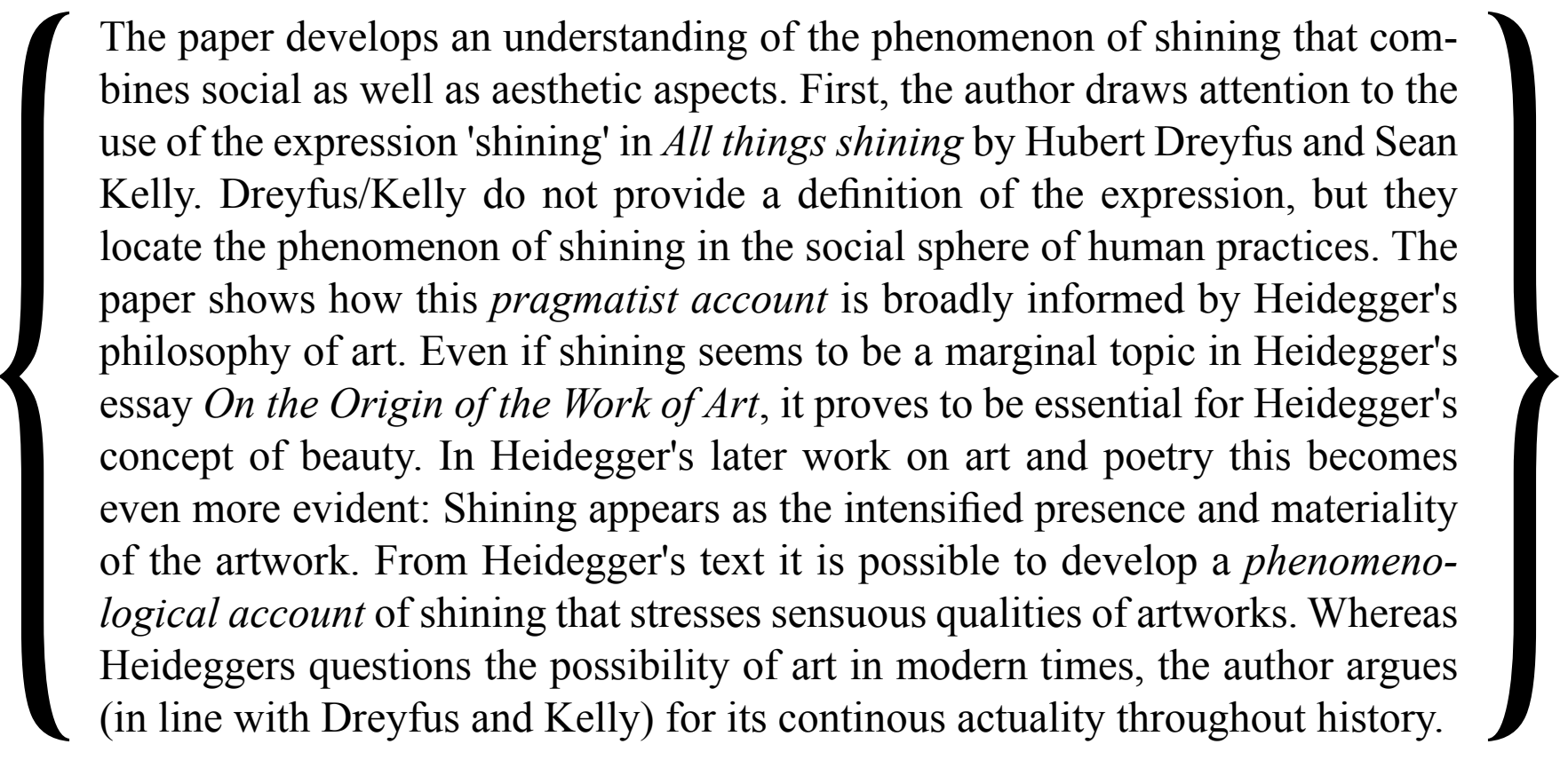

KEY-WORDS shining . Heidegger . On the Origin of the Work of Art 


\section{Dreyfus e Kelly sobre o 'brilho'}

All Things Shining não é um livro sobre Heidegger, mas reflete uma visão de mundo que é baseada em larga medida em uma leitura da filosofia de Heidegger. Hubert Dreyfus e Sean Kelly definem nossa época pelo seu caráter secular e pela ameaça do niilismo. ${ }^{1}$ Isso se encontra, de modo geral, em acordo com a postura crítica de Heidegger em face da modernidade e com sua compreensão da história da metafísica. Nessa perspectiva, a vida moderna parece ser ameaçada pela perda de sentido que é baseada em uma compreensão de ser enganosa. É famoso o argumento de Heidegger de que essa ameaça está enraizada na natureza da existência humana: a vida cotidiana nos impede de experimentar situações que proporcionam uma compreensão aprofundada da nossa existência. Em Ser e Tempo, Heidegger mostrou que a autocompreensão não pode ser alcançada sem decisões autênticas e que essas decisões são dificultadas pelo nosso repertório linguístico e pelas normas de nossas ações, enquanto amplamente coincidentes com convenções sociais inquestionadas. ${ }^{2}$ Contudo, é preciso vê-las como aquilo que são e levar em conta este conhecimento quando se escolhe entre diferentes opções. Dreyfus e Kelly apontam que o desafio de experimentar a vida como plena de sentido se torna ainda mais complicado quando nós nos defrontamos com o excesso de opções característico de uma sociedade moderna altamente desenvolvida. Ao invés de fazer escolhas autênticas ou de agir intuitivamente de um modo bem-sucedido, corre-se o risco de ficar preso em uma fútil autorreflexão. ${ }^{3}$

A ideia de niilismo certamente moldou aspectos importantes da cultura moderna e contemporânea. ${ }^{4}$ Contudo, é uma questão inteiramente diversa se a ameaça do niilismo deveria ser reconhecida como 'o' caráter que define nossa época presente. É surpreendente que Dreyfus e Kelly não forneçam argumentos filosóficos para essa visão. ${ }^{5}$ Ao invés de situar o niilismo em uma interpretação filosófica da história, eles recorrem à obra de David Foster Wallace para

1Cf. DREYFUS e KELLY, 2011, p. 12-21.

2 "O tipo de movimento da queda na e no interior da ausência de solo do ser impróprio no impessoal arranca a compreensão continuamente do projetar de possibilidades próprias e a arrasta para dentro da presunção tranquilizada de possuir ou alcançar tudo." HEIDEGGER, Sein und Zeit, p. 178.

3 DREYFUS e KELLY, 2011, p. 3-5.

4Para um endosso do niilismo como uma "oportunidade especulativa", que evita cair na tradição filosófica moderna de "reestabelecer o sentido da existência", ver: BRASSIER, 2007, p. 239.

5 Talvez isso se deva ao fato de que o livro se dirige a um público mais amplo do que aquele que publicações estritamente acadêmicas têm em vista. Em um contexto acadêmico, os autores provavelmente apoiariam seu diagnóstico dos tempos modernos com uma leitura de TAYLOR, 2007. 
descrever mais de perto a manifestação cultural do niilismo. ${ }^{6}$ Como consequência, All Things Shining parece se dirigir principalmente àqueles leitores que já compartilham a visão de que pode ser algo desafiador encontrar sentido na vida em meio ao mundo contemporâneo. Essa pressuposição, contudo, não deveria ser deixada inquestionada. Caso se queira distinguir a filosofia da expressão de uma visão de mundo ${ }^{7}$, a pressuposição deveria, ao menos, permanecer aberta ao debate. Além disso, pode-se argumentar que a complexidade das sociedades modernas torna impossível descrever seu estado atual sem reconhecer diferenças fundamentais entre os grupos e comunidades que constituem sociedades e que mantêm convicções divergentes. ${ }^{8}$

Dito isso, Dreyfus e Kelly conseguem mostrar que os clássicos da literatura fornecem um excelente material para um diagnóstico do tempo em que nós vivemos. Eles interpretam os escritos de Homero, Ésquilo, Dante, Melville e outros, de modo a sublinhar paradigmas de sucesso na lida com a vida. Sucesso é algo que pode ser medido pelo grau com que alguém cumpre ou excede suas próprias expectativas e aquelas de outras pessoas. Nesse contexto, a participação em práticas compartilhadas conta tanto quanto ações individuais em situações extraordinárias. Dreyfus e Kelly dão uma ampla variedade de exemplos. Ao interpretar a Ilíada, eles apontam o papel de Helena. Quando ela trai seu marido com Paris, seu comportamento pode ser criticado com base nas expectativas sociais que estão ligadas à ideia de casamento. Ainda assim, Homero apresenta sua paixão como algo louvável: “O que caracteriza a grandeza de Helena no mundo homérico é sua habilidade de viver uma vida que é constantemente suscetível à áurea Afrodite, o exemplo brilhante da dimensão erótica sagrada da existência.",

Em seus comentários a Homero, Dreyfus e Kelly recorrem a uma compreensão dos deuses gregos como forças que podem se manifestar momentaneamente na vida dos humanos. Assim, deuses e humanos estão relacionados uns aos outros pela sua própria natureza. Mais especificamente, a noção de divino está ligada a uma interpretação da experiência vivida. Nesse contexto, os deuses são

6 DREYFUS e KELLY, 2011, p. 22-57.

7 Uma distinção que era muito importante para o trabalho inicial de Heidegger. Ver: HEIDEGGER, Zur Bestimmung der Philosophie, GA 56/57, p. 3-12.

8 Toda tentativa de caracterizar "nossa época" por meio de uma única ameaça tem de enfrentar a incredulidade geral em face de um diagnóstico abrangente dos tempos, que Lyotard chamou de "incredulidade pós-moderna a respeito de metanarrativas". Ver: LYOTARD, 1984, p. xxiv.

9 DREYFUS e KELLY, 2011, p. 62. 
referidos como radiantes ou brilhantes. ${ }^{10}$ Os momentos da vida que são caracterizados pela sua presença se destacam:

Talvez essa seja uma lição sobre o sagrado que nós deveríamos considerar [atualmente]: quando as coisas estão em seu melhor momento, quando nós somos a versão mais excelente de nós mesmo que pode haver, quando nós estamos, por exemplo, trabalhando junto com os outros como um só, então nossa atividade parece ser extraída de nós por uma força externa. Esses são os momentos brilhantes na vida, momentos maravilhosos que requerem nossa gratidão. Nesses episódios de excelência, não importa em qual domínio, a voz de Odisseu deveria soar em nossos ouvidos: 'Fica em silêncio; freia teus pensamentos; não faças nenhuma pergunta. Isso é obra dos Olímpicos." "11

Esse louvor de uma atitude politeísta em face da vida não impede Dreyfus e Kelly de apresentar Jesus como um "exemplo brilhante de uma nova compreensão de fundo sobre o que é ser um ser humano."12 Ao interpretar a noção de $\dot{\alpha} \gamma \alpha \pi \eta ́$ como um chamado para entrar em uma certa tonalidade afetiva na qual alguém se relaciona com outras pessoas e com o mundo - uma Grundstimmung no sentido heideggeriano -, Dreyfus e Kelly tentam integrar ideias cristãs a uma moldura pluralista. Ishmael, o narrador de Moby Dick, de Melville, por sua vez, é interpretado como um "exemplo brilhante" de um homem que resiste à tentação de buscar uma "verdade única, universal" e, com êxito, vai ao encontro da pluralidade de perspectivas significativas em um mundo secular. ${ }^{13}$

Dreyfus e Kelly identificam esse ponto de vista pós-metafísico como o melhor modo de confrontar o perigo do niilismo na época atual. Se não há uma

10 Essa compreensão dos deuses gregos também pode ser encontrada na interpretação de Heidegger do Édipo de Sófocles: "Édipo, que ao início é o salvador e o senhor do Estado, no brilho [Schein] da glória e na graça dos deuses, é lançado para fora dessa aparência [Schein]. Essa aparência não é apenas a visão [Ansicht] subjetiva de Édipo de si mesmo, mas aquilo no interior do que acontece a aparição [Erscheinung] do seu ser-aí." HEIDEGGER, Einführung in die Metaphysik, GA 40, p. 114.

11 DREYFUS e KELLY, 2011, p. 81.

12DREYFUS e KELLY, 2011, p. 106.

13 DREYFUS e KELLY, 2011, p. 168. 
verdade única, universal, não há nenhuma pretensão razoável à absolutidade em qualquer domínio da sociedade. Esse ponto de vista tem a vantagem de dar suporte a uma abordagem esclarecida e liberal no que diz respeito a questões sociais e políticas. Contudo, é difícil defender filosoficamente esse tipo de pluralismo. A própria perspectiva pluralista, na medida em que ela tem de confrontar pontos de vista metafísicos, não corre o risco de se tornar uma teoria que demarca uma pretensão universal, a saber, a pretensão de que não há verdade universal? Em All Things Shining, essa questão não é colocada.

Outra dificuldade diz respeito ao significado da palavra 'brilho'. Dreyfus e Kelly referem-se repetidamente a "exemplos brilhantes", "momentos brilhantes", ou "coisas brilhantes" na vida, ${ }^{14}$ embora eles não expliquem exatamente o que querem dizer com "brilho". A partir dos usos da palavra, é possível inferir que os autores estão pensando em algo que se destaca, algo que excede o ordinário e que é amado e querido por aqueles que se deparam com isso. Além disso, é provável que a razão para o emprego frequente da metáfora do esplendor e do brilho tenha sido tomada da filosofia da arte de Heidegger. Embora o tópico do brilho (Schein) pareça ser um aspecto marginal na obra de Heidegger, uma leitura atenta das passagens em que Heidegger descreve obras de arte existentes mostra que ele associa constantemente a beleza da arte com o fenômeno do brilho. O modo como Dreyfus e Kelly situam o fenômeno do brilho parece depender das práticas de fundo de nossa cultura. Nesse sentido, eles fornecem uma compreensão pragmática do fenômeno do brilho. Dreyfus e Kelly concentram-se no sentido de brilho no interior de uma comunidade cultural. Mas, para compreender o fenômeno plenamente, é preciso se dar conta também de suas qualidades perceptivas. Para essa tarefa, a obra tardia de Heidegger fornece elementos valiosos.

\section{Beleza e 'Brilho'}

Há apenas algumas poucas passagens onde Heidegger fala explicitamente sobre a beleza. Uma delas se encontra no "posfácio" de A Origem da Obra de Arte, onde ele assinala que a beleza é inerente à verdade:

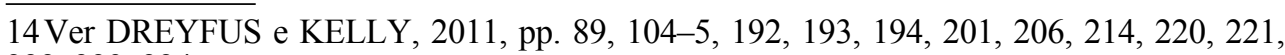
$222,223,224$ 
A verdade é a verdade do ente. A beleza não ocorre ao lado dessa verdade. Quando a verdade se põe em obra, ela aparece. Esse aparecer é, enquanto esse ser da verdade na obra e como obra, a beleza. Portanto, o belo pertence ao apropriar-se da verdade em meio ao acontecimento. Ele não é apenas relativo ao prazer, e puramente como o seu objeto. ${ }^{15}$

Nesse parágrafo, Heidegger se distancia da estética de Kant, de acordo com a qual a beleza existe apenas na relação do sujeito com um objeto estético. ${ }^{16} \mathrm{Na}$ visão de Heidegger, essa abordagem conduz a uma separação entre arte e verdade que é incapaz de fazer justiça ao impacto histórico da arte e da experiência estética. A arte é mais que uma questão de gosto, ela pode fornecer critérios para a autocompreensão de uma comunidade; quando isso ocorre, a arte também adquire um significado político. É por isso que Heidegger evita a separação entre o teórico e o prático e retorna a uma compreensão da beleza pela ligação da beleza com a verdade em um nível ontológico. Em uma passagem anterior do texto, ele dá uma indicação de como uma tal compreensão da beleza pode ser desenvolvida. Heidegger assinala como as obras de arte podem aparecer como belas:

Quanto mais simples e essencialmente o calçado é absorvido em sua essência, quanto mais despojada e puramente a fonte é absorvida em sua essência, tanto mais imediata e insinuantemente todo ente se torna, junto com eles, mais ente. Desse modo, o ser que se encobre é iluminado. A luz assim formada ajunta seu brilho na obra. O brilho ajuntado na obra é o belo. A beleza é um modo como a verdade enquanto desvelamento se essencia. ${ }^{17}$

15 HEIDEGGER, Der Ursprung des Kunstwerkes, GA 5, p. 69. Eis o texto original: "Die Wahrheit ist die Wahrheit des Seins. Die Schönheit kommt nicht neben dieser Wahrheit vor. Wenn die Wahrheit sich in das Werk setzt, erscheint sie. Das Erscheinen ist - als dieses Sein der Wahrheit im Werk und als Werk - die Schönheit. So gehört das Schöne in das Sichereignen der Wahrheit. Es ist nicht nur relativ auf das Gefallen und lediglich als dessen Gegenstand."

16 Kant compreende o belo enquanto o objeto de uma "satisfação" que é experimentada por meio de um "livre jogo da imaginação e do entendimento". Esse processo não tem uma regra determinada. Consequentemente, a arte - que é definida pela beleza - não pode fornecer nenhum tipo de conhecimento que seria significativo para além do reino estético. Cf. KANT, KU, p. B1-B74.

17HEIDEGGER, Der Ursprung des Kunstwerkes, GA 5, p. 43. Eis o texto original: "Je einfacher und wesentlicher nur das Schuhzeug, je ungeschmückter und reiner nur der Brunnen in ihrem Wesen aufgehen, um so unmittelbarer und einnehmender wird mit ihnen alles Seien- 
Três aspectos dessa passagem são dignos de nota. Primeiro, Heidegger enfatiza a simplicidade, pureza e imediatidade da arte em que ele está interessado. Segundo, o uso constante de adjetivos comparativos nessa passagem indica que uma obra de arte pode ser percebida como uma coisa que possui uma presença intensificada. Terceiro, e mais importante, Heidegger especifica o modo no qual a verdade se põe em obra na arte. Na obra de arte, a verdade ilumina o "raio" enquanto um desvelamento da verdade e, ao mesmo tempo, ela torna visível o encobrir-se necessário do ser. ${ }^{18}$ É por isso que a função ontológica da obra de arte é descrita por meio do uso metafórico das noções de luz, iluminação e brilho. Heidegger não explica por que ele utiliza essa linguagem, mas está claro que o potencial de iluminação é pensado como aquilo que distingue a obra de arte de outras coisas. A obra de arte é percebida como bela porque ela brilha. E essa forma específica de brilho não é enganadora, mas ligada à experiência da verdade. Além disso, o fenômeno do brilho está relacionado a qualidades sensíveis, o que se torna evidente na descrição de Heidegger da materialidade da obra de arte:

\begin{abstract}
A rocha vem ao sustentar e jazer e só assim vem a ser rocha; os metais vêm ao resplandecer e cintilar, as cores ao iluminar, os sons ao soar, a palavra ao dizer. Tudo isso vem à tona, na medida em que a obra se recolhe no maciço e pesado da pedra, no firme e flexível da madeira, na dureza e brilho do bronze, no iluminar e escurecer das cores, no ressoar do som e no poder nomeador da palavra. ${ }^{19}$
\end{abstract}

O resplendor é parte da presença fenomenal da materialidade da arte e tem de ser distinguido de uma forma imediata do belo da natureza. $\mathrm{O}$ brilho vem à tona somente quando a terra é incorporada nas obras de arte. Assim, a beleza

de seiender. Dergestalt ist das sichverbergende Sein gelichtet. Das so geartete Licht fügt sein Scheinen ins Werk. Das ins Werk gefügte Scheinen ist das Schöne. Schönheit ist eine Weise, wie Wahrheit als Unverborgenheit west."

$18 \mathrm{O}$ encobrir-se do ser é pensado por Heidegger como necessário, na medida em que, em sua aparição efetiva, entes particulares impedem a compreensão da possibilidade da aparição enquanto tal. Ver: HEIDEGGER, Der Ursprung des Kunstwerkes, GA 5, p. 48.

19 HEIDEGGER, Der Ursprung des Kunstwerkes, GA 5, p. 32. Eis o texto original: "Der Fels kommt zum Tragen und Ruhen und wird so erst Fels; die Metalle kommen zum Blitzen und Schimmern, die Farben zum Leuchten, der Ton zum Klingen, das Wort zum Sagen. All dieses kommt hervor, indem das Werk sich zurückstellt in das Massige und Schwere des Steins, in das Feste und Biegsame des Holzes, in die Härte und den Glanz des Erzes, in das Leuchten und Dunkeln der Farbe, in den Klang des Tones und in die Nennkraft des Wortes." 
das obras de arte encontra-se relacionada com sua materialidade. Heidegger não delineou essa conclusão em A Origem da Obra de Arte, mas, caso se queira compreender o conceito implícito de beleza inerente a sua compreensão da arte, a conexão entre brilho e materialidade tem de ser levada em conta.

$\mathrm{Na}$ obra tardia de Heidegger, podemos achar outras provas disso. Em sua primeira preleção sobre Nietzsche, $A$ Vontade de Poder como Arte, que Heidegger lecionou apenas um ano depois de escrever o ensaio sobre $A$ Origem $d a$ Obra de Arte, ele examina e critica a estética de Nietzsche. Na interpretação de Heidegger, a "vontade de poder" é o mais importante ensinamento da filosofia de Nietzsche, e ele a identifica como a culminação histórica da metafísica. $\mathrm{Na}$ visão de Heidegger, ao afirmar que tudo é governado pela vontade de poder, Nietzsche reduz o ser a um princípio subjetivo. Nesse contexto, a arte é compreendida como a "configuração suprema" [höchste Gestalt] da vontade de poder. ${ }^{\prime 20}$ A arte pode transformar a verdade em mera aparência e a mera aparência em verdade. As linhas entre o que é verdade e o que não é são tornadas tênues pela arte, em favor de uma perspectiva que intensifica a vida humana. Essa compreensão relativista da realidade, contudo, tem consequências problemáticas. A questão que se apresenta é a seguinte: como podemos saber que a arte de fato intensifica a vida, se ela nega a diferença entre verdadeiro e falso? Se nós compreendermos que a arte intensifica a vida, então o oposto tem de estar errado. Entretanto, essa conclusão não pode ser reconciliada com uma compreensão relativista da verdade. O próprio Heidegger estava ciente desse problema filosófico e de suas consequências para a compreensão nietzschiana da arte. Em sua preleção, Heidegger cita uma afirmação biográfica de Nietzsche, que foi publicada postumamente:

Muito cedo em minha vida tomei a questão da relação entre arte e verdade a sério: e ainda agora me encontro em um sagrado espanto perante essa discordância. ${ }^{21}$

Heidegger associa essa afirmação com a intenção de Nietzsche de superar o platonismo. É famosa a crítica de Platão ao papel dos poetas e artistas no Es-

20HEIDEGGER, Nietzsche: Der Wille zur Macht als Kunst, GA 43, p. 85.

21 HEIDEGGER, Nietzsche: Der Wille zur Macht als Kunst, GA 43, p. 87. Eis o texto original: "Über das Verhältnis der Kunst zur "Wahrheit bin ich am frühesten ernst geworden: und noch jetzt stehe ich mit einem heiligen Entsetzen vor diesem Zwiespalt." 
tado, mas, ao mesmo tempo, ele desenvolveu um conceito de beleza que liga a experiência estética à verdade do ser. A compreensão platônica de beleza como

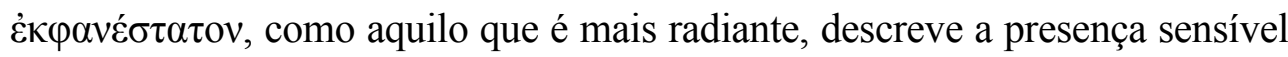
de uma ideia inteligível. Quando nós reconhecemos a ideia de algo, nossa percepção de suas qualidades sensíveis pode mudar. No Banquete, Platão descreve esse momento como uma transfiguração que cria um anseio por algo que existe verdadeiramente. ${ }^{22}$ Se o belo desperta o amor pela verdade, ele pode conduzir alguém a se envolver com a filosofia, o que pode aprimorar a vida de uma maneira eticamente relevante.

$\mathrm{Na}$ medida em que Nietzsche - ao menos na leitura de Heidegger - subordina a diferença entre a mera aparência e a verdade ao princípio da vontade de poder, o belo na compreensão nietzschiana não pode ter o efeito que Platão descreveu. De acordo com Nietzsche, o belo deve tornar-se um antídoto contra o niilismo, ainda que seja concebido como uma ilusão que, em última instância, não conduz para além do mundo finito e do perigo de uma perda existencial de sentido. Assim, permanece uma questão aberta como a postura relativista de Nietzsche sobre a verdade pode ser reconciliada com a ideia de que a vida não somente parece ser intensificada pela arte, mas é realmente intensificada por ela. Em outras palavras, a ideia de transformar a própria vida em uma obra de arte não fornece um critério que possa ser usado para medir o êxito de uma transformação estética de si próprio. Além disso, não está claro até que ponto o ideal de uma vida artística pode ser esclarecido pela filosofia. Quando Heidegger critica a filosofia da arte nietzschiana, ele estava ciente dos pressupostos conflitantes inerentes a ela. Todavia, a crítica de Heidegger à estética nietzschiana se baseia em uma leitura muito seletiva; seria possível até mesmo afirmar que ela é mais esclarecedora para a compreensão da própria posição de Heidegger que da de Nietzsche. Como mencionado acima, Heidegger liga repetidamente a experiência da beleza com uma compreensão de verdade enquanto desvelamento ou "clareira" (Lichtung) do ser. Além disso, Heidegger associa esse processo com o fenômeno do brilho. Ambos os pontos também são verdadeiros para a tradição platônica de pensamento sobre a beleza. Isso levanta a questão sobre se a filosofia da arte de Heidegger é capaz de abranger a ideia platônica de belo.

É interessante o fato de que Heidegger introduz um número de neologismos e expressões bastante originais nas passagens de sua preleção em que ele interpreta trechos centrais sobre a beleza nos diálogos platônicos. Ele escreve, por exemplo, que o belo é "aquilo que é mais luminoso e, enquanto tal, o que

22 PLATÃO, Banquete, 210e5-212a7 
mais nos atrai e o que mais nos liberta." 23 A experiência da beleza é apresentada como 'libertadora' nessa passagem porque ela pode inspirar alguém a ver as coisas como elas são verdadeiramente. $O$ belo tem o potencial de transformar a alma em direção a uma vida filosófica. Ainda que Heidegger não aborde esse potencial explicitamente, ele pode ser integrado a sua compreensão da arte. Quando a arte "instala um mundo", ela também tem de abrir espaço para o pensamento filosófico. ${ }^{24} \mathrm{~A}$ obra de arte pode fornecer um acesso intuitivo aos conceitos básicos, constitutivos da filosofia. Ao interpretar Platão em sua preleção sobre Nietzsche, Heidegger traduz de certo modo a compreensão platônica da beleza em seu próprio pensamento.

Contudo, ainda permanecem algumas diferenças cruciais entre a compreensão heideggeriana da beleza e o conceito platônico de belo. Enquanto Platão atribui o brilho à presença de uma ideia no reino do sensível, Heidegger tenta evitar a distinção clássica entre o sensível e o inteligível. Ele tenta evitá-la reiterando a tradição metafísica que tornou cada vez mais difícil na filosofia moderna apreender o ser como um todo. Essa é a razão pela qual ele associa o fenômeno do brilho com a materialidade da obra de arte e sua conexão com a terra. A terra inclui todo o sensível, embora não seja definida em oposição ao inteligível. Ela é concebida como algo significativo, e, ao mesmo tempo, como algo que escapa às restrições do conhecimento conceitual. E Heidegger não apresenta a terra em si mesma como 'radiante'. Ao invés disso, ela se torna radiante por meio de sua interação com a arte e sua integração às obras de arte reais. Heidegger também demarca a diferença entre os conceitos tradicionais de beleza e sua própria compreensão da beleza para assinalar a diferença entre concepções antigas e modernas.

Em Contribuições à Filosofia (Do Acontecimento Apropriador), Heidegger caracteriza seu próprio tempo como o "abandono de ser", que traz consigo a retração do divino, assim como a ausência de arte genuína. ${ }^{25}$ Contudo, Heidegger

23 HEIDEGGER, Nietzsche: Der Wille zur Macht als Kunst, GA 43, p. 243. Eis o texto original: "[Das Schöne] ist das Leuchtendste und als dieses das Fortziehendste und Entrückendste." A combinação dos três adjetivos na forma superlativa é bastante peculiar no texto original em alemão. Ao invés de se distanciar da afirmação de Platão, Heidegger escolhe um estilo de escrita enfático e altamente individual para sua tradução. Isso indica que - ao menos nessa passagem da preleção - a ideia de Platão se torna uma parte da sua própria linguagem e pensamento.

24 No ensaio A Origem da Obra de Arte, Heidegger descreve a criação da arte como um acontecimento que "instala um [novo] mundo". Ver: HEIDEGGER, Der Ursprung des Kunstwerkes, GA 5, p. 30-31. Isso significa que, de acordo com Heidegger, uma obra de arte original deveria contribuir de um modo decisivo para a emergência e autocompreensão histórica, social, política e religiosa de uma comunidade.

25 Ver: HEIDEGGER, Beiträge zur Philosophie (Vom Ereignis), GA 65, p. 116-119. 
não exclui a possibilidade de um "outro início", no qual a arte contribui para uma nova fundação do ser. Quando ele descreve a transição para o outro início, ele alude novamente à beleza e ao esplendor da arte:

\begin{abstract}
Mas a arte é, enquanto vindoura, o pôr-se em obra da verdade (ou ela não é nada) - uma fundação essencial da essência da verdade. De acordo com essa medida suprema é que tem de ser medido aquilo que gostaria de se apresentar como arte - como o caminho para deixar a verdade de tornar ente naquele ente, que enquanto obra transporta de modo encantador os homens para a interioridade do seer, na medida em que os arrebata da luminosidade do desvelado e, então, afina-os e determina-os para a guarda da verdade do ser. $^{26}$
\end{abstract}

De acordo com essa passagem, a experiência da beleza por meio da arte contém o potencial para mudar a relação entre homem e ser. O desvelado se torna luminoso por meio da arte, e esse acontecimento fornece uma visão sobre a essência da necessidade de preservação. As mesmas reservas com respeito a uma imagem uniforme, secular do mundo contemporâneo mencionadas acima também se aplicam à compreensão heideggeriana da modernidade como um tempo que é abandonado pelo ser. Heidegger não tinha a intenção de criar uma imagem abrangente do mundo moderno, mas isso ocorre em sua descrição dos modos nos quais a modernidade supostamente carece de "ser" ou tem de ser caracterizada como sendo "abandonada pelo ser". Ele dá uma descrição unilateral da modernidade que ignora a pluralidade de instâncias e interesses de grupos diversos. Ainda que a crítica heideggeriana da metafísica e sua filosofia da técnica tenham sido muito influentes no pensamento do século XX, isso não significa que elas forneçam uma compreensão abrangente das condições modernas da existência humana. Além disso, é digno de nota que haja uma certa mudança na compreensão de Heidegger acerca da história entre sua obra na década de 1930 e após a guerra. Essa mudança afeta também sua compreensão da

26 HEIDEGGER, Grundfragen der Philosophie, GA 45, p. 190. Eis o texto original: "Die Kunst aber ist künftig - oder sie ist gar nicht mehr - das Ins-Werk-setzen der Wahrheit - eine wesentliche Gründung des Wesens der Wahrheit. Nach diesem höchsten Maß ist Jegliches zu messen, was als Kunst auftreten möchte - als der Weg, die Wahrheit seiend werden zu lassen in jenem Seienden, das als Werk den Menschen in die Innigkeit des Seyns entzückt, indem es ihn aus der Leuchte des Unverhüllten berückt und so zum Wächter der Wahrheit des Seyns stimmt und bestimmt." 
arte. Dito brevemente, após a Segunda Guerra Mundial, Heidegger está menos interessado no pensamento sobre mudanças fundamentais e a transição para o outro início. Ele começa a prestar mais atenção nos fenômenos efêmeros e marginais. Ele também se torna cada vez mais interessado na experiência do belo.

\section{O belo na correspondência com Staiger}

Entre o fim de 1950 e o início de 1951, Heidegger manteve uma correspondência com o crítico e teórico da literatura Emil Staiger. A correspondência começou após uma conferência de Staiger na Universidade de Freiburg sobre o poema de Eduard Mörike intitulado Sobre um lampião (Auf eine Lampe). A tradução do poema diz:

Ainda não demovido, belo lampião, tu adornas,

Dependurado aqui delicadamente em leves cadenas,

O teto da alcova já quase esquecida.

Sobre tua alva taça marmórea, cuja borda

A coroa de hera em verde e áureo bronze entrelaça,

Envolve-a alegre um círculo de crianças em ciranda.

Como instiga tudo isso! jocoso, embora um suave espírito

Do solene espraie sobre toda a forma -

Autêntica criação de arte! E quem a ela atenta?

Mas o que é belo, brilha venturoso em si mesmo.

[parece encontrar ventura, selig scheint es] $]^{27}$

27 HEIDEGGER, Aus der Erfahrung des Denkens, GA 13, p. 93. O poema no original diz: " Noch unverrückt, o schöne Lampe, schmückest du, / An leichten Ketten zierlich aufgehangen hier, / Die Decke des nun fast vergessnen Lustgemachs. / Auf deiner weißen Marmorschale, deren Rand / Der Efeukranz von goldengrünem Erz umflicht, / Schlingt fröhlich eine Kinderschar den Ringelreihn. /Wie reizend alles! lachend, und ein sanfter Geist / Des Ernstes doch ergossen um die ganze Form-- /Ein Kunstgebild der echten Art. Wer achtet sein?/ Was aber schön ist, / selig scheint es in ihm selbst." 
De acordo com a interpretação de Staiger do poema de Mörike, dever-se-ia ler no último verso da tradução em português "parece encontrar ventura", enquanto Heidegger sugere que a tradução "brilha venturoso [venturosamente]" seria a interpretação correta. Essa diferença se deve ao fato de que a palavra alemã scheinen possui dois significados distintos: (1) 'brilhar', 'aparecer' e (2) 'meramente parecer como algo'. No caso do poema de Mörike, o significado de es scheint somente pode ser determinado por meio da interpretação. Heidegger afirma que o lampião no poema de Mörike tem de ser compreendido como uma obra de arte e que Mörike pensava nele como algo belo no sentido do conceito hegeliano de beleza:

Enquanto "um produto artístico [da criação] de tipo genuíno", o lampião, "aquilo que reluz", é o $\sigma v ́ v \beta o \lambda o v$ da obra de arte enquanto tal - "do ideal", na linguagem de Hegel. O lampião, a composição estética ("Ó, belo lampião"), une [duas coisas] junto em uma só: o brilho físico e o brilho da ideia enquanto essência da obra de arte. Enquanto uma composição estética linguística, o poema é ele mesmo o símbolo, que repousa na linguagem, da obra de arte em geral..$^{28}$

Com essa leitura, Heidegger desafia a interpretação de Staiger acerca da obra de Mörike, mas o teórico da literatura defende sua visão com a ajuda de argumentos históricos, os quais, por sua vez, estimulam Heidegger a explicar sua interpretação com maior detalhe. Ao final da notável correspondência, Staiger faz um compromisso: já que é possível que o último verso do poema tenha sido intencionalmente concebido para ser ambivalente, ambas as leituras do poema poderiam ser consideradas legítimas. A partir disso, não faria sentido avaliar qual interpretação seria a mais apropriada à intenção original do poeta. O que é mais importante sobre toda a correspondência, contudo, é o fato de que Heidegger se sentiu impelido a defender sua interpretação. Se o poema de Mörike não lhe importasse, ele não teria escrito uma carta a Staiger.

28HEIDEGGER, Aus der Erfahrung des Denkens, GA 13, p. 95. Eis o texto original: "Die Lampe, ,das Leuchtende' ist als ein Kunstgebild echter Art das $\sigma 0 ́ \mu \beta 0 \lambda$ ov des Kunstwerkes als solchen - in Hegels Sprache ,des Ideals‘. Die Lampe, das Kunstgebild (o schöne Lampe), bringt in eines zusammen: das sinnliche Scheinen und das Scheinen der Idee als Wesen des Kunstwerkes. Das Gedicht selbst ist als sprachliches Kunstgebilde das in der Sprache ruhende Symbol des Kunstwerkes überhaupt." 
Dessa forma, é muito provável que ele considerasse o poema como uma obra de arte que não pertence simplesmente ao passado, mas que ainda fala hoje aos seus leitores. Consequentemente, a afirmação de que a modernidade não possui arte genuína não pode ser defendida, ainda que apenas porque a arte de séculos passados ainda é acessível a uma audiência moderna. Falando metaforicamente, Heidegger assume que o lampião no poema de Mörike ainda brilha, ele permanece belo ainda hoje. Ele pode ser lido como um poema que mostra a beleza de uma criação artística e as qualidade sensíveis de sua presença. O poema evoca a imagem de um lampião, inspirando a imaginação do espectador e motivando-o a olhar mais de perto para perceber os detalhes e a presença física desse objeto particular. ${ }^{29} \mathrm{O}$ poema aponta para a "alva taça marmórea", a "coroa de hera em verde e áureo bronze" e um "círculo de crianças em ciranda". Esses são detalhes que podem passar despercebidos na vida cotidiana, mas que chamam a atenção para si quando esse objeto particular é reconhecido como uma obra de arte. Esse potencial fenomenológico da arte é significativo para além do tempo da criação do poema. Para descrevê-lo com maior precisão, seria preciso voltar-se para a fenomenologia da percepção, ao invés de orientar-se por uma filosofia especulativa da história.

Apesar disso, Heidegger associa o poema de Mörike com a situação hermenêutica de seu autor e afirma que o poema abre um mundo: "a coroa de hera e o círculo de crianças pertencem à composição estética do belo lampião, na medida em que este espacializa de modo clareador o mundo da alcova." ${ }^{30} \mathrm{O}$ contexto histórico e social particular de uma "alcova" do século XIX pode ser algo passado. Contudo, esse contexto torna-se acessível por meio do poema. Assim, o próprio fato de que Heidegger empregue aqui o conceito de "mundo" do modo como ele o usou em A Origem da Obra de Arte pode ser tomado como uma outra indicação de sua suposição implícita de que a obra de Mörike permanece um exemplo válido para a arte em geral e pode até mesmo ter um significado existencial para um leitor moderno.

Por outro lado, Heidegger também associa a poesia de Mörike à estética de Hegel. Nessa leitura, o lampião é um símbolo para a obra de arte no sentido hegeliano conforme descrito nos Cursos de Estética. Heidegger, contudo, recusa explicitamente a definição de Hegel. Todavia, se Heidegger quisesse reduzir o poema a um exemplo substituível para o ponto de vista estético de Hegel, não

29 Para a importância da imaginação para a compreensão da arte, ver: SALLIS, 2000, p. 215-230.

30 HEIDEGGER, Aus der Erfahrung des Denkens, GA 13, p. 104. Eis o texto original: "Efeukranz und Kinderschar gehören zum Kunstgebilde der schönen Lampe, insofern diese die Welt des Lustgemachs lichtend einräumt." 
haveria razão para que ele insistisse em sua leitura contra a de Staiger. O esplendor contínuo que ele atribui ao lampião é oposto ao juízo de Hegel de que a arte se tornou "algo do passado".

Na década de 1950, a compreensão da arte de Heidegger se altera em direção a um ponto onde a diferença entre presente e passado parece ser menos importante para ele do que ela era em A Origem da Obra de Arte. O pathos revolucionário e a agenda nacionalista são substituídos por uma postura mais pluralista a respeito da arte. Isso acarreta um novo foco em coisas efêmeras e marginais, assim como uma atenção maior à presença sensível de tudo aquilo que "brilha". A obra de arte brilha não somente por causa de seu significado em um contexto social, mas por causa de suas qualidades sensíveis que atraem nossa atenção para ela e inspiram nossa imaginação. Assim, a consideração pragmática da qualidade do brilho tem de ser complementada por uma consideração fenomenológica. ${ }^{31}$

\section{Conclusões}

Caso se adote uma postura pluralista em face de obras de arte diversas, tanto de períodos iguais quanto de períodos diversos, surge a seguinte questão: qual é o lugar da história na filosofia da arte? Tanto a crítica de Heidegger à modernidade quanto a tentativa de Dreyfus e Kelly de definir a época presente como uma era secular ameaçada pelo niilismo superestimam obviamente a diferença entre períodos históricos e a diferença entre as obras de arte que pertencem a eles. O próprio fato de autores como Kelly e Dreyfus encontrarem algo de significativo nos clássicos de praticamente todas as épocas principais da história do Ocidente mostra que a história está organizada muito mais por continuidade e por elementos de sentido mutuamente superpostos do que por crises e mudanças e perdas radicais.

A insistência de Heidegger em sua interpretação do poema de Mörike, Sobre um Lampião, é uma outra prova dessa continuidade. Não obstante, na medida em que a arte tem de ser compreendida como uma "prática cultural", ela se encontra sempre ligada a normas sociais de um período histórico particular. ${ }^{32}$ Ao

31 Uma consideração fenomenológica do belo da arte, que é muito mais devedora da estética kantiana que da filosofia da arte de Heidegger, foi feita por: FIGAL, 2015. Figal, contudo, não considera a interpretação pragmática do "brilho". Assim, o potencial social e ético da arte permanece marginal para a compreensão de Figal da estética.

32 Para uma compreensão da arte como uma prática cultural que é caracterizada por seu poten- 
investigar as relações entre arte e sociedade, podemos alcançar uma compreensão melhor da razão pela qual uma obra de arte particular "importava", por que ela era considerada significativa por uma audiência particular. Contudo, compreender por que uma obra de arte "importa" no presente - independentemente de sua proveniência - implica uma consideração fenomenológica de sua beleza. Uma tal consideração consiste em uma descrição dos modos nos quais uma obra de arte "brilha". Enquanto uma consideração acerca da beleza nas obras de arte, ela incluirá uma descrição da presença sensível que faz ela se destacar em um ambiente e inspira a imaginação do espectador.

Quando Heidegger sublinha a importância da materialidade de uma obra de arte, isso pode ser interpretado como uma consideração fenomenológica do brilho. A arte nos permite ver os materiais de um modo que nós não podemos experimentá-los quando são usados por razões puramente práticas. Um poema sobre um lampião pode mudar o modo como nós percebemos a luz artificial e o quarto que é iluminado por ele. Nesse caso, uma obra literária atrai a atenção para uma coisa que abriga o potencial de aparecer como bela em si mesma. Mas o fenômeno do brilho não está restrito ao domínio da arte. Dreyfus e Kelly mostraram de modo convincente que as ações humanas e as práticas habituais podem brilhar em certas situações do mesmo modo que traços de personagens literárias o fazem - e, quando o fazem, eles aparecem como belos. A ligação entre o ético e o estético, que também poderia ser rastreada de volta a Platão, é constitutiva do fenômeno do brilho.

cial reflexivo, ver: BERTRAM, 2014, p. 15.

Recebido em: 15.06.2015 | Aprovado em: 09.07.2015

\section{Referência Bibliográfica}

BRASSIER, Ray. Nihil Unbound: Enlightenment and

Extinction. London: Palgrave Macmillan, 2007.

BERTRAM, Georg. W. Kunst als menschliche Praxis. Berlin: Suhrkamp, 2014.

DREYFUS, Hubert; KELLY, Sean D. All things shining. Reading the Western Classics to Find Meaning in a Secular Age. New York: Free Press, 2011.

FIGAL, Günter. Aesthetics as Phenomenology. The
Appearance of Things. Trad. Jerome Veith. Bloomington and Indianapolis: Indiana University Press 2015.

HEIDEGGER, Martin. Aus der Erfahrung des Denkens, 1910-1976 (Gesamtausgabe 13). Frankfurt am Main: Klostermann, 1983.

Basic Questions of Philosophy, Selected "Problems" of "Logic". Trad. Richard Rojcewich e André Schuwer. Bloomington and Indianapolis: Indiana University Press, 1994. 
Being and Time. Trad. Joan Stambaugh. Albany: SUNY Press, 2010.

.Beiträge zur Philosophie (Vom Ereignis) (Gesamtausgabe 65). Frankfurt am Main: Klostermann, 1989.

. Contributions to Philosophy (Of the Event).

Trad. Richard Rojcewicz and Daniela Vallega-Neu. Bloomington and Indianapolis: Indiana University Press, 2012.

. Der Ursprung des Kunstwerkes (1935/36).

In: Holzwege (Gesamtausgabe 5). Frankfurt am Main: Klostermann, 1977.

. Grundfragen der Philosophie, Ausgewählte

„Probleme“ der ,Logik" (Gesamtausgabe 45). Frankfurt am Main: Klostermann, 1984.

. Nietzsche: Der Wille zur Macht als Kunst (Gesamtausgabe 43). Frankfurt am Main: Klostermann, 1985.

. Einführung in die Metaphysik (Gesamtausgabe 40). Frankfurt am Main: Klostermann, 1983.

. Introduction to Metaphysics. 2a ed. Trad. Gregory Fried e Richard Polt. New Haven (CT): Yale University Press, 2014

. Nietzsche. Trad. David Farrell Krell. San Franciscio: Harper \& Row, 1979.

. Sein und Zeit (Gesamtausgabe 2). Frankfurt am Main: Klostermann, 1977.

. The Origin of The Work of Art (1935-36). In:

Off the Beaten Track. Trad. Julian Young e Kenneth Haynes. Cambridge: Cambridge University Press, 2002.

. The Staiger-Heidegger Correspondence.

Trad. Arthur A. Grugan. In: Man and World (1981),
Vol. 14, Issue 3, pp. 291-307.

. Towards a Definition of Philosophy. Trad Ted Sadler. London: Continuum, 2008.

. Zur Bestimmung der Philosophie (Gesamtausgabe 56/57). 2a ed. Frankfurt am Main: Klostermann, 1999.

KANT, Immanuel. Critique of the Power of Judgment. Trad. Paul Guyer e Eric Matthews. Cambridge: Cambridge University Press, 2000.

LYOTARD, Jean-François. The postmodern condition . Trad. Geoff Bennington e Brian Massumi. Minneapolis: University of Minnesota Press, 1984.

PLATÃO. Symposion. In: Platonis Opera (Vol. 2). Ed. Jon Burnet. Oxford: Clarendon, 1901.

SALLIS, John. The Force of Imagination. Bloomington and Indianapolis: Indiana University Press, 2000.

TAYLOR, Charles. A Secular Age. Cambridge (MA): Harvard University Press, 